\title{
Application of an experiential model of learning; using martial arts in educational settings
}

Charles SPRING*

College of Business. University of Derby (United Kingdom)

\author{
5th IMACSSS World Scientific Congress Abstracts, Rio Maior (Portugal), October 6-8 \\ Section: Psychological, pedagogic and didactics in MA\&CS \\ Type: Oral communication
}

\section{Introduction}

This presentation is to discuss the application of an experiential learning and teaching model that can be applied in a variety of different educational settings (Spring, 2015a). The model has been applied in educational institutions from primary schools, further educational colleges (16-18 years old) as well as higher educational programmes in universities. It has been used in the United Kingdom, Germany and Finland. The martial arts experiential model has evolved from the work undertaken by the author in several different educational settings, primarily the development and successful delivery of a BA (Hons) programme in Martial Arts Theory and Practice.

\section{Methodology}

An ethnographical observational approach was taken in delivering sessions in the university setting originally. Focus groups were used with students before and after delivered sessions to assess the students preferred learning styles and feedback based on their experiences of the sessions (Spring, 2015b).

\section{Results}

The findings indicate that when applied the experiential model creates interest for the students, especially those who are kinaesthetic learners as indicated by Kolb, Boyatzis and Mainemilis (1999) and Beard (2002). Results for students engaging in these modules of study had on average higher achievement levels. In the school setting engagement in the learning activities was also seen very positively by the educators involved with the students.

\section{Discussion and conclusion}

In the context of martial arts there arguably a high amount of experiential opportunity for study, and as indicated use and application of martial arts is a lot about sense making of the environment around the individual. By developing and establishing a university degree in the subject and applying the concepts of experiential learning was an essential aspect for inclusion, to gain buy in from students (Spring, 2015a). This is also exemplified through the concept of continuing professional development and the idea of professionalization with the martial arts. In martial arts the student is forever, once you get a black belt many believe that is when you start learning. Beard (2002) also emphasises that experiential learning can be used in a range of educational settings and is not limited in is use in the classroom or in a practical environment. 


\section{References}

Beard, C. (2002). The Power of Experiential Learning: A Handbook for Trainers. UK: Kogan Page Limited. Kolb, D. A, Boyatzis, R. E., \& Mainemelis, C. (1999). Experiential Learning Theory: Previous Research and New Directions. In R. J. Sternberg \& L. F. Zhang (Eds.), Perspectives on cognitive, learning, and thinking styles (pp. 227-247). Mahwah, NJ,: Lawrence Erlbaum.

Spring, C. (2015a). Martial Arts: Applications in Higher Education. UK: Ex-L-Ence Publishing.

Spring, C. (2015b). The increasing need for practitioner research in martial arts coaching and teaching Presented at the Craven College Sport Sciences Conference, $15^{\text {th }}$ October

Key words: Experiential learning; martial arts; educational model.

Study supported by the "Programa Unificado de Bolsas de Estudo para Estudantes de Graduação" from São Paulo University (USP) 2015-2016. 